\title{
COLLISIONS OF ROAD VEHICLES WITH BRIDGE COLUMNS
}

\author{
Ervin Kožoman \\ Josip Juraj Strossmayer University of Osijek, Faculty of Civil Engineering Osijek, mag.ing.aedif. \\ Hrvoje Draganić \\ Josip Juraj Strossmayer University of Osijek, Faculty of Civil Engineering Osijek, Assistant Professor \\ Corresponding author: draganic@gfos.hr \\ Damir Varevac \\ Josip Juraj Strossmayer University of Osijek, Faculty of Civil Engineering Osijek, Associate Professor
}

\begin{abstract}
As speed limits and traffic on city roads continue to increase, collisions between road vehicles and bridge columns are becoming more common. Current regulations analyze collision with one major simplification: replacing dynamic action with the equivalent static force. In the present paper, we develop a numerical model of a typical Croatian overpass and loaded it with an equivalent static load according to the EN1991-7 and ASSHTO LRFD provisions, analyzing the differences in overpass behavior between them. We compared this to a simplified dynamic analysis, which assumed the impact forces to be impulse loads. Protection measures can be installed around bridge columns that reduce the probability of vehicle collision and open possibilities for reducing collision forces.
\end{abstract}

Keywords: collision, impact force, impulse, static and dynamic analysis, provisions

\section{UDAR MOTORNOG VOZILA U STUP MOSTA}

Sažetak: Udar vozila u stup mosta više nije rijetkost, ponajviše zbog sve veće opterećenosti prometnica i povećanja dopuštenih brzina vozila. Problem udara obrađen je u propisima uz znatno pojednostavljenje, dinamičko djelovanje zamijenjeno je ekvivalentnim djelovanjem statičke sile. Izrađen je numerički model tipičnog mosta na hrvatskim cestama na koji je primijenjena sila udara prema EN1991-7 i ASSHTO LRFD propisima kako bi se pokazala razlika između preporučenih djelovanja. Izvedena je dodatna usporedba s pojednostavljenim dinamičkim proračunom, gdje je sila udara pretpostavljena kao impulsno opterećenje. Oko stupova mostova mogu biti postavljene zaštitne mjere koje umanjuju vjerojatnost pojave udara i omogućavaju smanjenje veličina sila korištenih u proračunu.

Ključne riječi: udar vozila, sila udara, impuls, statička i dinamička analiza, propisi 


\section{INTRODUCTION}

Bridges must handle many kinds of loads and actions. Besides the action of the bridge's own weight, bridges experience must carry traffic loads and cope with accidental loads such as earthquakes, explosions, floods, landslides, and vehicle collisions [1]. After traffic loads exceeding bridge bearing capacity and floods, collisions of vehicles or ships is the third most common cause of bridge collapse. Collision occurs over a very short time, transferring enormous kinetic energy between the fast vehicle and fixed bridge column. This is an impulse action with all the characteristics of dynamic load. To simplify the situation for practical engineering use, the dynamic load of a collision can be replaced with an equivalent static load. These simplifications are allowed because the peak intensities of real, dynamic actions affect the structure over such a short time that the structure cannot properly respond to them.

Because heavy trucks have been a rapidly growing part of traffic loads in the past twenty years, especially on highways, there are more collisions between vehicles and bridge columns that cause bridges to collapse. This problem is particularly serious in the People's Republic of China, where rapid industrial development has increased traffic loads along all main traffic routes. A series of studies has been done in the United States to determine the origin of collisions between vehicles and bridge columns, assessing the risks of collision and finding appropriate design models [2-7]. Based on these studies, several protection systems for bridges have been developed in an attempt to minimize accidents.

Estimates show that in the state of New York in the U.S. alone, there are more than 200 collisions between vehicles and bridges every year [1]. These accidents often cause human casualties and disrupt traffic (Figure 1), and they can pollute the land and water if the colliding vehicle is carrying dangerous substances. Beyond the U.S. [7], the People's Republic of China, Australia, and Canada have also reported cases of bridge collapse.

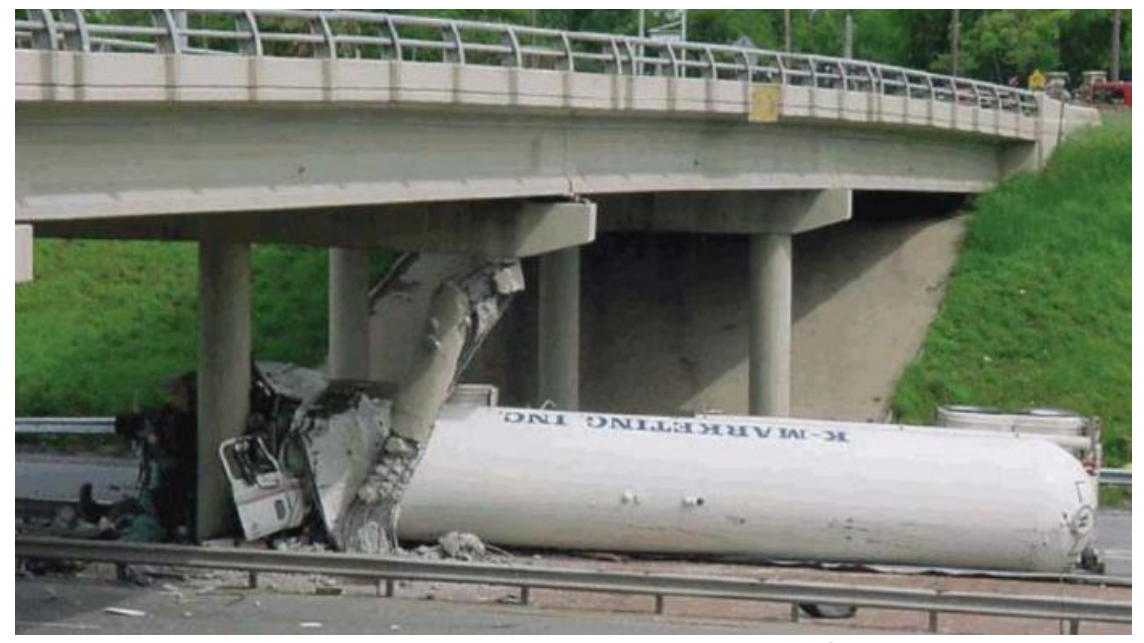

Figure 1 Impact between vehicle and column (U.S. highway) [8]

Detailed research on this issue dates back to the early 1990s, when a systematic approach was adopted in order to create new regulations that included guidelines for designing bridge columns that could withstand accidental loads such as vehicle collisions. Ko [9] investigated criteria for loads caused by vehicle collision on Great Britain highways, compared loads obtained by risk analysis with recommendations given in national codes and proposed improvements to the regulations. El-Tawil [7] developed a numerical model for collisions between vehicles and bridge columns, drawing the following conclusions: AASHTO regulations are adequate for collisions of light and moderate vehicles, but heavy vehicles require more stringent criteria. Geedipally at al. [10] provided a risk assessment of heavy vehicles colliding with bridge columns and analyzed two risk cases. The first case accounted for road characteristics in the load assessment, while the second case did not. The most influential factors in this risk assessment were lane width and bridge location (road curve).

In the present work, we compare the current European and U.S. codes, establishing whether equivalent static models can accurately describe the dynamic action of collision. 


\section{PROVISION APPROACHES}

A vehicle collision is a short-term, accidental load of significant magnitude that is unlikely to occur to a given structure during its design lifetime. Although the action itself might not be accidental, it can be classified as such because it is rare. Because of its rarity, there is insufficient data on collisions to perform a statistical analysis that would provide satisfactory values of impact loading on structures. Vehicle collision must be treated as an accidental load and must be applied to bridge design as such [11].

\subsection{EN1991-1-7}

EN 1990 introduces the concept of consequence classes, which represent the consequences of failure of part or all of a structure (Table 1). It is impossible to eliminate risk, and in most cases it is necessary to accept a certain risk level, determined by various factors such as the potential casualties, economic consequences, and cost of safety measurements [12].

Table 1 Consequence classes (EN 1990 Annex B) [12]

\begin{tabular}{cll}
\hline $\begin{array}{c}\text { Consequences } \\
\text { Class }\end{array}$ & \multicolumn{1}{c}{ Description } & \multicolumn{1}{c}{$\begin{array}{c}\text { Examples of buildings and civil engineering } \\
\text { works }\end{array}$} \\
\hline CC3 & $\begin{array}{l}\text { High consequence for loss of human life; very great } \\
\text { economic, social, or environmental consequences. }\end{array}$ & $\begin{array}{l}\text { Grandstands, public buildings } \\
\text { consequences of failure are high (e.g., concert } \\
\text { halls). }\end{array}$ \\
\hline CC2 & $\begin{array}{l}\text { Moderate consequences for loss of human life; } \\
\text { considerable economic, social, or environmental } \\
\text { consequences. }\end{array}$ & $\begin{array}{l}\text { Residential and office buildings, public buildings } \\
\text { where consequences of failure are moderate } \\
\text { (e.g., office buildings). }\end{array}$ \\
\hline CC1 & $\begin{array}{l}\text { Low consequences for loss of human life; small or } \\
\text { negligible economic, social, or environmental } \\
\text { consequences. }\end{array}$ & $\begin{array}{l}\text { Agricultural buildings where people do not } \\
\text { normally enter (e.g., storage buildings), } \\
\text { greenhouses. }\end{array}$ \\
\hline
\end{tabular}

EN 1991-1-7 [13] gives two strategies for minimizing these risks. The first strategy is to identify accidental actions, and the second to limit localized failure. The Eurocode does not accurately define how to identify an accidental action; even so, it is possible to define accidental actions as all possible actions, no matter how low their probability. For bridges, the following actions may be considered:

- impacts from road vehicles, trains, or ships with piers, decks, or other structural members

- fire caused by colliding trucks carrying flammable products

- the scour effect around bridge piers and abutments for a bridge in a riverbed

- overloading caused by unauthorized heavy vehicles

Localized failure assumes that in an accidental event, part but not all of the structure fail. This assumption is appropriate for bridges. Generally, EN 1991-1-7 suggests adopting strategies for accidental situations based on the consequence classes defined in Table 1, defining bridges as CC2 and sometimes as CC3. CC2 bridges are designed using simplified analysis with an equivalent static action to implement all the design rules. Different parts of a structure can be assigned different consequence classes; for example, a lower consequence class can be given to parts that can be monitored, maintained, and replaced regularly, such as cables and bearings. For CC3 structures, because they have the highest risk of casualties, it may be necessary to use risk analysis and refined methods such as dynamic analysis and non-linear models to assess the interactions between the load and the structure [11].

EN 1991-1-7 defines hard and soft impact [11]: hard impact is a collision in which the energy dissipates mostly by the colliding body, while soft impact is a collision in which the structure deforms and absorbs the impact energy. Hard impact deforms the colliding body, while soft impact deforms the structure. Collisions are generally classified between hard and soft because both the collider and the target absorb some energy. Because the bridge column or pier has higher stiffness than the vehicle, the impact load is determined by assuming a rigid structure: that is, by using a hard impact model. In this case, the impact force may be represented by an equivalent static force. 
EN 1991-1-7 defines a vehicle as a truck with a maximum gross weight of greater than 3.5 tons. Experiments using such trucks have been conducted in several European countries in order to study how columns behave in collisions. Experimental investigations provide design values of forces depending on the traffic conditions, impact area, and height of the impact point. For hard impact, the design model defines impact force for two perpendicular directions: $F_{\mathrm{dx}}$ parallel to the direction of normal travel and $F_{\mathrm{dy}}$ perpendicular to the direction of normal travel. These two forces are normally not accounted for simultaneously. The force position is defined by a height, $h$, above the level of the carriageway or higher, where there are certain protective barriers (Figure 2) [13].

Table 2 Equivalent static forces [13]

\begin{tabular}{cccc}
\hline Road class & $\boldsymbol{F}_{d x}[\mathrm{kN}]$ & $\boldsymbol{F}_{d y}[\mathrm{kN}]$ \\
\hline Highways and state roads & & 1000 & 500 \\
\hline County roads & & 750 & 375 \\
\hline City and other roads & & 500 & 250 \\
\hline \multirow{2}{*}{ Courtyards and garages } & Cars & 50 & 25 \\
\cline { 2 - 4 } & Trucks & 150 & 75 \\
\hline
\end{tabular}

Table 3 Recommended impact heights and areas [13], [11]

\begin{tabular}{|c|c|c|c|c|}
\hline & \multicolumn{2}{|c|}{ Impact height } & \multicolumn{2}{|c|}{ Impact area $(a \cdot b)$} \\
\hline & EN1991-1-7 & AASHTO & EN1991-1-7 & AASHTO \\
\hline Trucks & $\begin{array}{c}0.50 \mathrm{~m} \leq h \leq 1.50 \mathrm{~m} \\
\text { (or more for protective } \\
\text { barriers) }\end{array}$ & $h=1.20 \mathrm{~m}$ & $\begin{array}{c}a=0.5 \mathrm{~m} \\
b=\min \left\{\begin{array}{l}1.5 \mathrm{~m} \\
\text { column width }\end{array}\right.\end{array}$ & $\begin{array}{l}a \leq 1.50 \mathrm{~m} \\
b \leq 0.60 \mathrm{~m}\end{array}$ \\
\hline Cars & $h=0.50 \mathrm{~m}$ & $-1-$ & $\begin{array}{c}a=0.25 \mathrm{~m} \\
b=\min \left\{\begin{array}{l}1.5 \mathrm{~m} \\
\text { column width }\end{array}\right.\end{array}$ & $-1-$ \\
\hline
\end{tabular}

The values in Table 2 depend on various factors such as the expected traffic density, type of traffic, and any protection for the bridge columns and piers. The correction factors are given in Annex $C$ and depend on the distance $s$, as shown in Figure 2 [13].

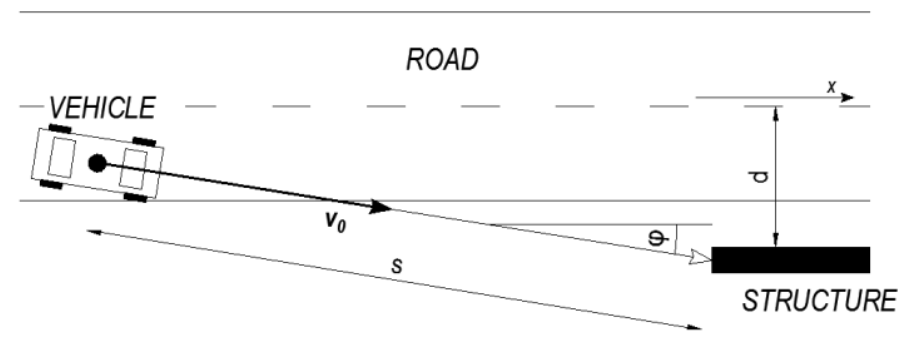

Figure 2 Vehicle-column distance [13]

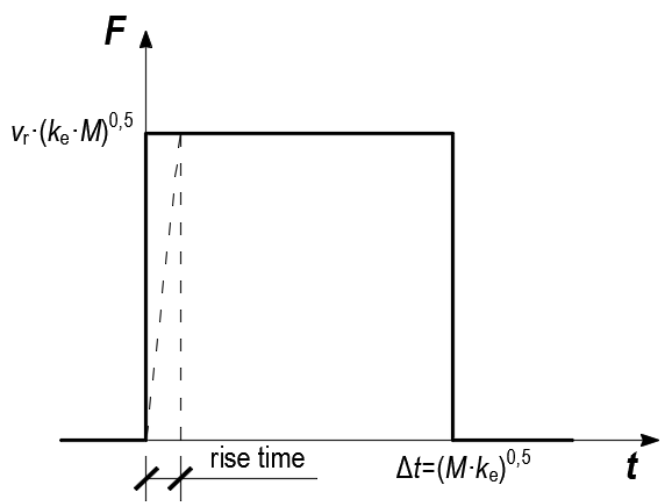

Figure 3 Idealized impact pulse model [13]

Annex C of EN1991-1-7 also provides guidance on approximating the design dynamic action of structures experiencing accidental impacts by road vehicles. It also distinguishes hard impact and soft impact. The maximum impact force is derived by equating the initial kinetic energy of the impacting vehicle to either the strain energy of the vehicle (for hard impact) or that of the impacted structure (for soft impact), giving the following equation: 


$$
F=v_{r} \sqrt{k_{e} \cdot M}
$$

where $v_{r}$ is the vehicle velocity at impact, $k_{e}$ is the equivalent elastic stiffness of the vehicle (for hard impact) or that of the impacted structure (for soft impact), and $M$ is the mass of the impacting vehicle. This equation is based on a simple elastic single-degree-of-freedom idealization of the problem, assuming that one of the impacting bodies is rigid and immovable. Annex $\mathrm{C}$ also suggests that the calculated impact force can be treated as a rectangular dynamic impulse on the surface of the structure, as shown in Figure 3, with the duration calculated as:

$$
\Delta t=\sqrt{M / k_{e}}
$$

Note that Eq. (1) neglects the interaction between the vehicle and the structure, underestimating the impact force for hard impact and overestimating it for soft impact. In addition, it does not consider the plastic behavior of the impacting vehicle or the structure $[14,15]$.

\subsection{AASHTO LRFD}

AASHTO (American Association of State Highway and Transportation Officials) [16] provisions are guidelines for designing, assessing, and rehabilitating bridges on U.S. highways, made to ensure the structures are durable and stable for regular conditions and loads, and to ensure their resistance to vehicle collisions and other extreme loads.

The design rules in these regulations implement the Load and Resistance Factor Design (LRFD) methodology. They determine factors based on reliability theory, itself based on the current knowledge of statistical parameters of the loads and construction of the bridge. The AASHTO LRFD methodology mandates that bridges be designed using a limit state in order to maximize security and usability while respecting affordability and aesthetics. Several limit states are defined in order to create a usable bridge that can safely transfer the design load over the determined time period. The resistance of bridge components is based on nonelastic behavior, although the loading effects are determined using elastic analysis. This inconsistency, present in most provisions for bridges, comes from incomplete knowledge of these structures' non-elastic behavior.

Among its important requirements, the AASHTO LRFD requires that bridges have minimum vertical and horizontal clearances. These minimums reduce the number of vehicle impacts and possible damage to the structure. The vertical clearance under a bridge must be at least $5.3 \mathrm{~m}$, while the horizontal clearances prohibit objects from being placed within $1.2 \mathrm{~m}$ from the far edge of the road [16].

Current AASHTO LRFD provisions mandate that bridge piers and abutments with no protection must have a design impact force of $1800 \mathrm{kN}$, and that the distance between the structure and the edge of the road must be less than $10 \mathrm{~m}$. That force should be applied in a horizontal plane that is $1.2 \mathrm{~m}$ above the ground plane in the most critical direction. The chosen intensity of this force comes from an analysis of vehicle impact. For a single column, according to AASHTO LRFD regulation, the load should be applied as a concentrated force; in contrast, if a column is a wall, the load can be concentrated or distributed over the most appropriate area, considering the proportions, but cannot be greater than $150 \mathrm{~cm}$ in width and $60 \mathrm{~cm}$ in height. These measures depend on the front-end size of the vehicle impacting the column. Some shortcomings of the AASHTO LRFD provisions are:

1. The design impact force is not defined as a function of the design speed nor of the vehicle characteristics.

2. There is no mention of the dynamic interaction between the vehicle and bridge structure.

3. There are no guidelines on designing the bridge so that it does not collapse at the moment of impact.

\section{NUMERICAL RESEARCH}

We designed and implemented a numerical model in SAP2000 software [17]. The numerical model of the overpass was loaded with impact forces, calculated according to recommendations given in EN1991-1-7 and ASSHTO LRFD. We performed linear static and dynamic analyses, comparing the maximum column forces at the top and bottom of the column. Based on these results, we give an overall assessment of the methods used to obtain adequate impact forces and column responses. 


\subsection{Bridge geometry}

The bridge geometry we used is characteristic of Croatian roads; it is the standard geometry for overpasses bridging highways, railroads, and other roads [18]. We used a standard overpass-shown in Figure 4, Figure 5, and Figure 6-for our analysis of collisions between vehicles and bridge columns. The plate superstructure is 9.0 $\mathrm{m}$ wide, $90 \mathrm{~cm}$ thick, and has two spans of $14.0 \mathrm{~m}$; the total overpass length is $28.0 \mathrm{~m}$. The overpass superstructure is supported at the midpoint of the total length by two columns, each with a height of $7.5 \mathrm{~m}$ (Figure 4 and Figure 6). Each column has a circular cross-section with a diameter of $1.0 \mathrm{~m}$ and is made of reinforced concrete (concrete class C35/45, elastic modulus $E_{c}=33298 \mathrm{~N} / \mathrm{mm}^{2}$ ) and reinforced with steel (B500B, elastic modulus of $E_{\mathrm{s}}=210000 \mathrm{~N} / \mathrm{mm}^{2}$ ). The columns are fixed in a shallow reinforced-concrete foundation with dimensions of $9.0 \times 2.0 \times 1.0 \mathrm{~m}$.

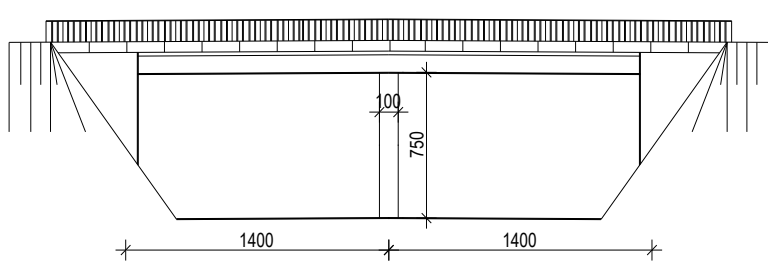

Figure 4 View of the overpass

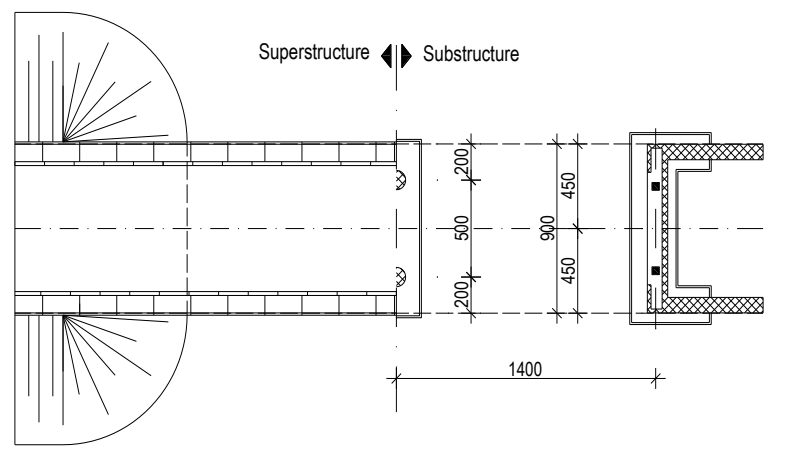

Figure 5 Overpass superstructure and substructure
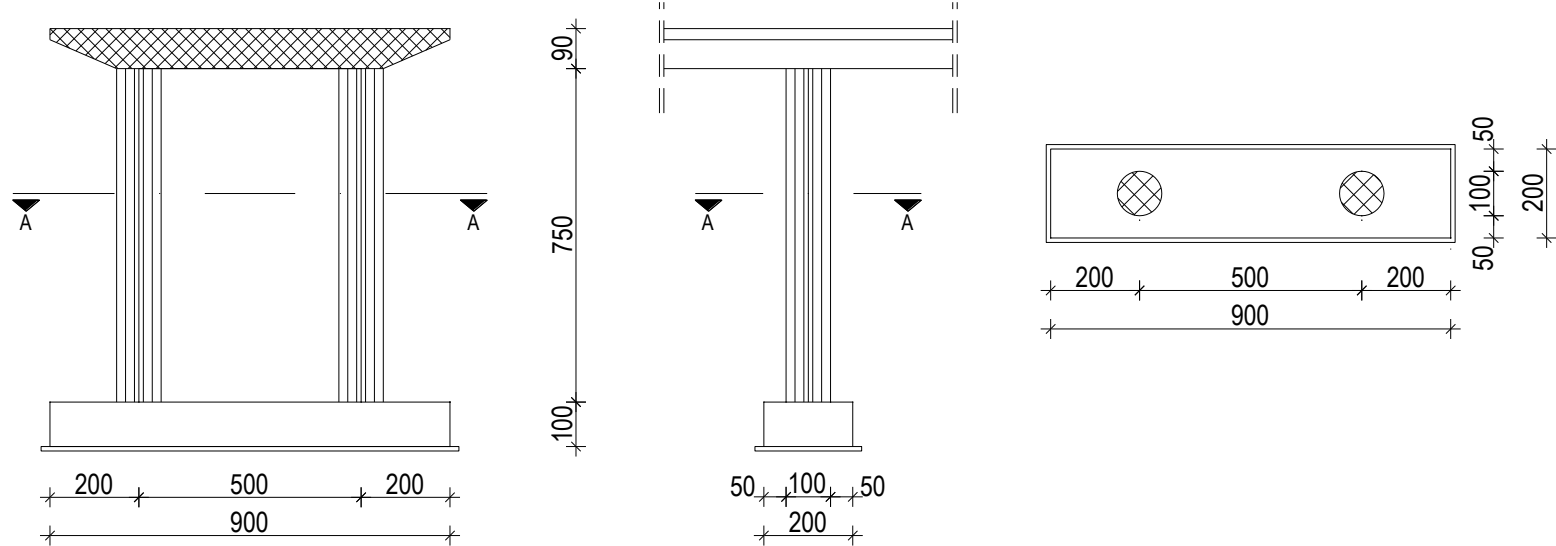

Figure 6 Overpass cross-section and columns

\subsection{Numerical model}

The overpass superstructure was modeled as a continuous slab over two spans, with free boundary conditions in the longitudinal direction and fixed boundary conditions in the transversal and vertical directions. The superstructure is rigidly connected to the supporting columns, and the columns ends are fixed supports. The slab superstructure was modeled as a shell element with a thickness of $90 \mathrm{~cm}$, and a finite element mesh of $25 \times 25 \mathrm{~cm}$ was applied to shell elements. The columns were modeled using beam elements with mesh lengths of $10 \mathrm{~cm}$. Figure 7 shows the numerical model of the overpass. We conducted both linear-elastic static and dynamic analyses. 


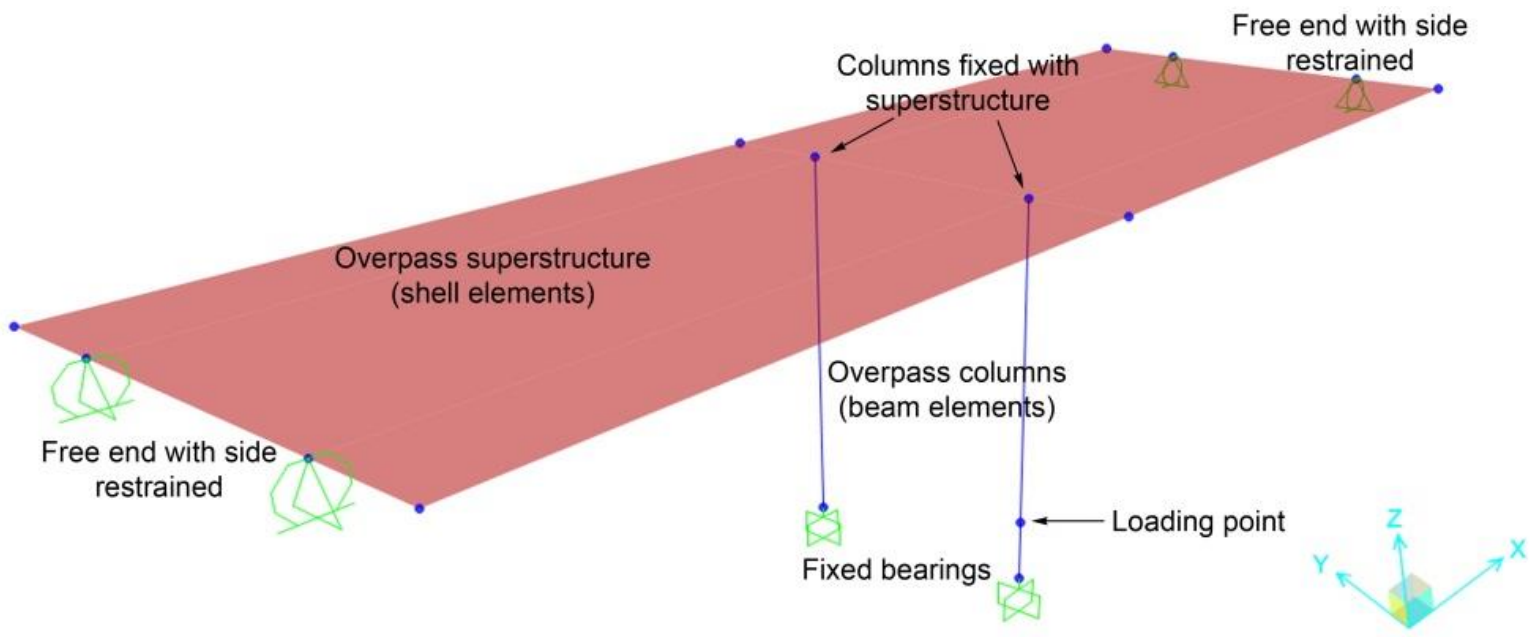

Figure 7 Numerical model of the overpass (SAP2000)

Calculating the impact force of a vehicle requires knowledge of its stiffness. Our calculations use the results of crash-testing new passenger vehicles from the New Car Assessment Program (NCAP). Swanson et al. [19] used passenger cars tested under the NCAP to evaluate three stiffness methodologies, hypothesizing that passenger cars would have dramatically differences vehicle stiffness among the 1982-2001 model years. Initially, they determined the static and dynamic stiffness and used them to calculate the impact force. Initial attempts to quantify a vehicle's stiffness characteristics were done using the early portion of the force-deflection profiles. These profiles were generated using the force exerted on the barrier plotted against the dynamic deformation of crush that the vehicle experienced during testing. The static stiffness was obtained using only the measured postcrash static crush. This does not account for vehicle rebound or the elastic behavior exhibited by the vehicle frontend. The maximum crush, needed to determine the static stiffness using an energy equation, was determined from the difference between the vehicle length before and after the test. Accelerometers mounted in the vehicle were used to estimate the maximum dynamic displacement. The dynamic displacement was calculated from the maximum of the double integral of vehicle acceleration. Vehicle rebound is incorporated into the calculation. Table 4 lists the car classes and their average stiffness values for the 1982-2001 model years. Detailed tables of vehicle stiffness and measured deformation can be found in Swanson et al. [19].

Table 4 Average stiffness of passenger cars from NCAP tests [19]

\begin{tabular}{cccccc}
\hline \multirow{2}{*}{ Car class } & \multicolumn{2}{c}{ Test Weight [kg] } & Initial Stiffness & Static Stiffness & Dynamic Stiffness \\
& Min. & Max. & & 1.1.1.1.1.1.1 [N/mm] & \\
\hline Mini & 839.0 & 1065.0 & 908.80 & 988.40 & 462.40 \\
Light & 1066.0 & 1292.0 & 1040.00 & 997.60 & 611.00 \\
Compact & 1293.0 & 1519.0 & 1134.80 & 1164.20 & 649.40 \\
Medium & 1520.0 & 1746.0 & 1175.20 & 1242.60 & 701.20 \\
Heavy & 1746.0 & $>$ & 1414.40 & 1218.00 & 743.60 \\
\hline Average (all) & 1292.8 & & 1136.80 & 1167.20 & 670.60 \\
\hline
\end{tabular}

The overpass used can be found on all types of Croatian roads-highways, local roads, urban areaswhere speed limits are regulated according to road type. Roads in urban areas have speed limits of $50 \mathrm{~km} / \mathrm{h}$, local roads have speed limits of $70 \mathrm{~km} / \mathrm{h}$ or $90 \mathrm{~km} / \mathrm{h}$, and highways have speed limits of $130 \mathrm{~km} / \mathrm{h}$. However, these limits do preclude higher speeds. Here, we assume that the overpass is on a highway and that the vehicle is moving at a maximum of $130 \mathrm{~km} / \mathrm{h}$, which we assume to be the impact speed if the vehicle lost steering control while driving. With the stiffness and vehicle mass, we determined the impact force using Eq. (1) and the impulse duration using Eq. (2). Table 5 and Table 6 list the impact forces and impulse durations for various vehicle speeds. The impact forces are applied to the overpass column in the driving direction at a height of $1.2 \mathrm{~m}$ for trucks and $0.5 \mathrm{~m}$ for cars, measured from the road surface (Figure 7 ). 
Table 5 Impact forces for various truck speeds

\begin{tabular}{|c|c|c|c|c|c|}
\hline \multicolumn{2}{|c|}{ Trucks } & Mass [kg] & Speed $[\mathrm{km} / \mathrm{h}]$ & Impact force [kN] & Impulse duration, $t$ [s] \\
\hline \multirow{2}{*}{ Static analysis } & AASHTO & - & - & 1800 & - \\
\hline & EN1991-1-7 & - & - & 1000 & - \\
\hline \multirow{8}{*}{ Dynamic analysis } & \multirow{4}{*}{ AASHTO } & \multirow{4}{*}{36000} & 130 & 5908.29 & 0.998 \\
\hline & & & 90 & 4090.35 & 1.200 \\
\hline & & & 70 & 3181.39 & 1.361 \\
\hline & & & 50 & 2272.42 & 1.610 \\
\hline & \multirow{4}{*}{ EN1991-1-7 } & \multirow{4}{*}{30000} & 130 & 5393.51 & 0.911 \\
\hline & & & 90 & 3733.97 & 1.095 \\
\hline & & & 70 & 2904.20 & 1.242 \\
\hline & & & 50 & 2074.43 & 1.470 \\
\hline
\end{tabular}

Table 6 Impact forces for a car at $130 \mathrm{~km} / \mathrm{h}$ (highway)

\begin{tabular}{lccc}
\hline \multicolumn{1}{c}{ Passenger cars } & Mass $[\mathrm{kg}]$ & Impact force [kN] & Impulse duration, $\boldsymbol{\Delta t}[\mathbf{s}]$ \\
\hline AASHTO & 1400 & 1131.43 & 0.197 \\
EN1991-1-7 & 1500 & 1171.14 & 0.204 \\
\hline Heavy & 1746 & 1301.17 & 0.220 \\
Medium & 1520 & 1178.92 & 0.205 \\
Compact & 1293 & 1046.40 & 0.189 \\
Light & 1066 & 921.59 & 0.172 \\
Mini & 839 & 711.26 & 0.152 \\
\hline
\end{tabular}

\section{RESULTS AND DISCUSSION}

We monitored and compared the shear forces $\left(F_{\mathrm{y}}\right)$ and moments $\left(M_{\mathrm{y}}\right)$ in the driving direction at the loading point, the base of the column, and the top of the column. Table 7 and Table 8 show the results of numerical analysis for various car stiffnesses and driving speeds for trucks and cars, respectively. These results show some differences in the static and dynamic analyses. For trucks, the static analysis gives much smaller shear forces and moments than the dynamic analysis. If the shear forces from dynamic analysis are compared to the static analysis from the AASHTO provision, the dynamic analysis gives results up to 6.8 times higher than those from static analysis. Compared to the EN provision, the results from dynamic analysis are up to 13 times larger than those of static analysis. The moments obtained by dynamic analysis show the same trend: they were up to 5.3 times larger than AASHTO, and up to 10.3 times larger than EN, obtained by static analysis. Comparing dynamic analyses, the EN results are $9.5 \%$ smaller than the AASTHO results. This difference occurred because the AASHTO dynamic analysis used a higher vehicle mass than the EN dynamic analysis (Table 5).

We performed a similar comparison for cars. These results are significantly less different than those for trucks, because the different car classes have a balanced mass distribution. The masses used in the provisions are the median masses used in the NCAP tests. This might be an underestimation because the analysis showed that the heavy car class produces $15 \%$ higher forces than the provisional car masses. The underestimation of impact force could be explained by the smaller probability of a heavy car appearing on the road; most vehicles are medium or compact, which are very similar in mass to the provisional cars.

Table 7 Results of numerical analysis for trucks

\begin{tabular}{|c|c|c|c|c|c|c|c|c|}
\hline \multirow{2}{*}{ Analysis type } & \multirow{2}{*}{ Provision } & \multirow{2}{*}{ Speed } & \multicolumn{3}{|c|}{ Shear force, $F_{y}[\mathrm{kN}]$} & \multicolumn{3}{|c|}{ Bending moment, $M_{x}[\mathrm{kNm}]$} \\
\hline & & & T.P. & L.P. & B.P. & T.P. & L.P. & B.P. \\
\hline \multirow{2}{*}{ Static } & AASHTO & - & -123.94 & 1676.06 & 1676.06 & 290.87 & -489.94 & 1521.33 \\
\hline & EN1991-1-7 & - & -68.92 & 931.08 & 931.08 & 161.94 & -272.28 & 845.01 \\
\hline \multirow{8}{*}{ Dynamic } & \multirow{4}{*}{ AASHTO } & 130 & -962.93 & 6529.05 & 6529.05 & 1823.81 & -1832.30 & 5963.28 \\
\hline & & 90 & -666.70 & 4520.10 & 4520.10 & 1262.85 & -1268.53 & 4128.40 \\
\hline & & 70 & -518.58 & 3515.64 & 3515.64 & 982.38 & -986.64 & 3210.78 \\
\hline & & 50 & -370.47 & 2511.17 & 2511.17 & 701.90 & -704.76 & 2293.53 \\
\hline & \multirow{4}{*}{ EN1991-1-7 } & 130 & -879.05 & 5960.18 & 5960.18 & 1664.96 & -1672.66 & 5443.64 \\
\hline & & 90 & -608.62 & 4126.28 & 4126.28 & 1152.88 & -1158.01 & 3768.70 \\
\hline & & 70 & -473.41 & 3209.33 & 3209.33 & 896.84 & -900.68 & 2931.20 \\
\hline & & 50 & -338.20 & 2292.37 & 2292.37 & 640.80 & -643.36 & 2093.70 \\
\hline
\end{tabular}


Table 8 Results of numerical analysis for cars

\begin{tabular}{lcccccc}
\hline \multicolumn{1}{c}{ Analysis case } & \multicolumn{3}{c}{ Shear force, $\boldsymbol{F}_{\boldsymbol{y}}[\mathrm{kN}]$} & \multicolumn{3}{c}{ Bending moment, $\boldsymbol{M}_{\boldsymbol{x}}[\mathrm{kNm}]$} \\
& T.P. & L.P. & B.P. & T.P. & L.P. & B.P. \\
\hline AASHTO & -46.75 & 1462.60 & 1462.60 & 76.94 & -117.44 & 613.03 \\
EN1991-1-7 & -48.38 & 1513.94 & 1513.94 & 79.62 & -121.56 & 634.55 \\
Heavy & -53.73 & 1681.81 & 1681.81 & 88.35 & -135.04 & 704.91 \\
Medium & -48.70 & 1524.10 & 1524.10 & 80.14 & -122.38 & 638.81 \\
Compact & -43.23 & 1352.17 & 1352.17 & 71.20 & -108.57 & 556.75 \\
Light & -38.09 & 1190.58 & 1190.58 & 62.79 & -95.60 & 499.02 \\
Mini & -19.44 & 919.11 & 919.11 & 48.67 & -73.80 & 385.23 \\
\hline
\end{tabular}

Figure 8 and Figure 9 show the column shear forces and moments over time. The applied impact forces were calculated at a car speed of $130 \mathrm{~km} / \mathrm{h}$. The force and moment time-histories are very similar, with a slight difference only in peaks, but this difference is expected because the loading curves were similar in shape but different in load. The trends for shear forces and moments match for all car types until around $0.25-0.30 \mathrm{~s}$; after that, random peaks appear because the different car types have different impulse durations. For trucks, the shapes of the shear forces and moment time-histories are very similar to those of cars; the only difference is the larger peak intensities of the shear forces and moments, as well as the longer response time caused by the longer impulse durations (Table 5 and Table 6).

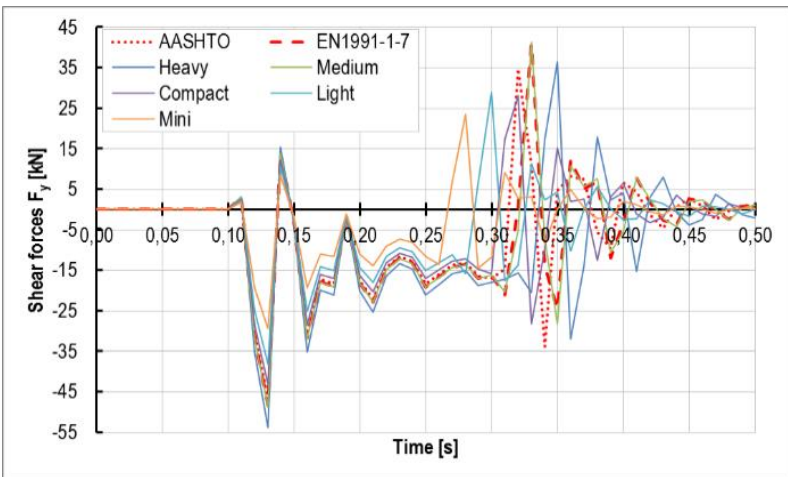

Figure 8 Column shear forces at the top

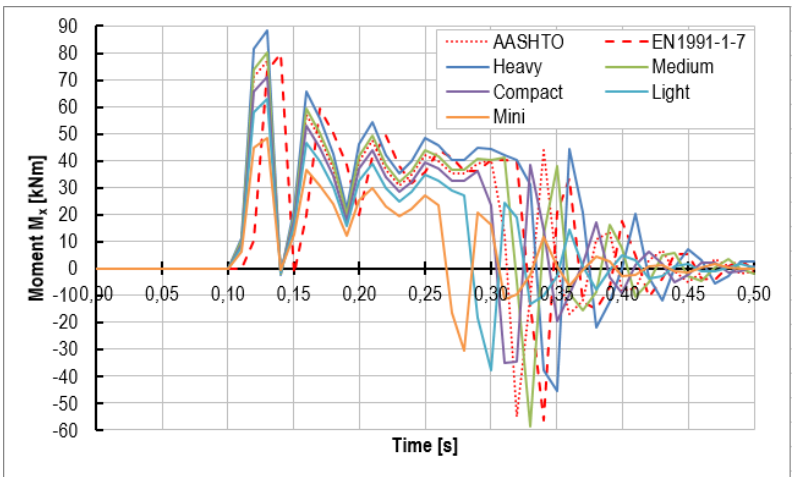

Figure 9 Column moments at the top

The numerically calculated bending moments are within the column bearing capacity if the column reinforcement has a reinforcement ratio of $1.6 \%$ or higher. While the bending moments are within capacity, the base shear forces are well beyond the yielding limit, which can cause column failure at the base point (Figure 1). Installing protective barriers [20] around vulnerable bridge columns can reduce impact forces, decreasing internal forces and avoiding the need to strengthen the column itself.

\section{CONCLUSION}

We analyzed the EN 1991-1-7 and AASHTO LRFD provisions for vehicle impact loads, using them to determine the static and dynamic vehicle impact forces on a bridge column. Our calculations yield dynamic impact forces that are significantly larger than the static forces because of the high vehicle mass proposed by the provisions. The proposed truck mass is 30 tons for EN1991-1-7 and 36 tons for AASHTO LRFD, producing dynamic impact forces of $5393.51 \mathrm{kN}$ and $5908.29 \mathrm{kN}$, respectively, at a vehicle speed of $130 \mathrm{~km} / \mathrm{h}$. These forces are 5.3 and 3.3 times larger, respectively, than the proposed static impact forces. The differences are somewhat smaller in the impact forces for passenger cars. To calculate the impact force, we used the NCAP test results of car stiffness values and masses.

A numerical model of an overpass column was loaded with calculated impulses and shear forces, and the bending moments were analyzed. Because of the larger impact forces exerted on the bridge column in the dynamic analysis, the internal forces were larger than those given by static analysis. The column internal forces obtained by dynamic analysis for medium-class cars were very similar to those obtained by static analysis for the 
proposed impact forces. This similarity comes from the similar masses of the cars. According to the NCAP tests, a medium car has an average mass of $1520 \mathrm{~kg}$, very similar to those proposed by EN1991-1-7 (1500 kg) and AASHTO LRFD (1400 kg). The time-histories of shear forces and bending moments for various vehicle class had the same shape because the loading impulse were similar in shape but differed in peak intensities and durations. The bending moments were within bearing capacity, while the base shear forces were well beyond the yielding limit, which could cause column failure at the base point. Dynamic analysis generated more-conservative results-larger impact forces and displacements-but if protective rails are used, then a simple static analysis is adequate.

Impact protection measures for vehicle/bridge column collision are inevitable, and the most commonly used protections are conventional elastic-steel guard rails and concrete New Jersey barriers. Increased use of high-tension cable rail barriers is expected because they have many advantages over conventional barriers. Croatian provisions for road signs, signalization, and road equipment [21] list these protection barriers as a possible means of impact mitigation. A detailed numerical analysis should be conducted on 3D solid columns and car models, incorporating vehicle stiffness and deformation capacity in addition to column stiffness in order to better investigate the dynamic behavior of columns and to determine if the proposed static forces are adequate for designing bridge columns directly impacted by a fast vehicle.

\section{References}

[1] Agrawal, A.; Chen, C. 2008: Bridge vehicle impact assessment, University Transportation Research Consortium New York State Department of Transportation, pp. 1-28.

[2] Bedi, A. K. 2000: Study of a typical bridge girder damaged by vehicle impacts, in Proceedings of the 2nd Forensic Engineering Congress, San Juan, Puerto Rico.

[3] Fu, C. 2001: Maryland Study, Vehicle Collision with Highway Bridges. Contract No. SP907B1, Maryland State Highway Administration, The Bridge Engineering Software and Technology Center, Department of Civil Engineering, University of Maryland.

[4] Fu, C.; Burhouse, J.; Chang, G.-L. 2004: Overheight vehicle collisions with highway bridges, Transportation Research Record: Journal of the Transportation Research Board, 1865, pp. 80-88. http://dx.doi.org/10.3141/1865-12

[5] Horberry, T.; Halliday, M.; Gale A. G. 2002: Bridge strike reduction: optimising the design of markings, Accident Analysis \& Prevention, 34(5), pp. 581-588. DOI: 10.1016/S0001-4575(01)00055-0

[6] Martin, A.; Mitchell, J. 2004: Measures to Reduce the Frequency of Over-Height Vehicles Striking Bridges: Final Report. Unpublished Report, PPAD9/100/61, Department of Transport, UK.

[7] El-Tawil, S. 2004: Vehicle collision with bridge piers, University of Michigan, Department of Civil and Environmental Engineering, pp. 1-83.

[8] Buth, C.E. et al. 2010: Analysis of large truck collisions with bridge piers: phase 1. Report of guidelines for designing bridge piers and abutments for vehicle collisions.

[9] Ko, R. 2004: Vehicle collision loading criteria for bridge piers, in Henderson Colloquium: Designing for the consequences of hazards, A. Martin, Ed., Cambridge. pp. 1-6.

[10] Geedipally, S. R.; Lord, D.; Buth, C. E. 2010: Estimating the Crash Risk Involving Heavy Vehicles and Bridge Piers, pp. 1-19.

[11] Dutta, S.; Roy, R. 2012: Performance of seismically designed buildings under blast loading, Iranian Journal of Science and Technology, Transactions of Civil Engineering, 36.

[12] EN1990; 2001: Eurocode 0: Basis of structural design, Brussels, Belgium: European Committee for Standardization.

[13] EN1991-1-7; 2006: Eurocode 1: Actions on structures - Part 1-7: general actions - Accidental actions, Brussels, Belgium: European Committee for Standardization.

[14] Al-Thairy, H. A.; Wang, Y. 2014: Behaviour and design of steel columns subjected to vehicle impact, 566, Trans. Tech.

Publ. DOI: 10.4028/www.scientific.net/AMM.566.193

[15] Stojić, D.; S. Conić, S. 2013: Structural vehicle impact loading, Facta universitatis-series: Architecture and Civil Engineering, 11(3), pp. 285-292. DOI: 10.2298/FUACE1303285S 
[16] AASHTO, L.: Bridge Design Specification (2007) American Associate of State Highway and Transportation Officials, Washington, D.C.

[17] Wilson, E. L. 1997: SAP2000: integrated finite element analysis and desing of structures. Analysis reference: Computers and Structures.

[18] Radić, J.; Mandić, A; Puž, G. 2005: Konstruiranje mostova. Mostovi 2 Zagreb: Hrvatska sveučilišna naklada, pp. 1-664.

[19] Swanson, J. et al. 2003: Evaluation of stiffness measures from the US new car assessment program, in 18th Int. Technical Conf. of the Enhanced Safety of Vehicles.

[20] Maze, T. H. et al. 2009: Analysis of Safety Benefits for Shielding of Bridge Piers.

[21] Schleyer, G. et al. 2007: Experimental investigation of blast wall panels under shock pressure loading, International Journal of Impact Engineering, 34(6), pp. 1095-1118. DOI: 10.1016/.j.jimpeng.2006.05.006 